\title{
The Role of Hiding Information in Information Systems on Organization Continuation and Strength
}

\author{
Victor Setrag George Soultanian \\ Al-Balqa' Applied University \\ Aqaba University Collage \\ Finance and Management Department \\ Aqaba-Jordan
}

\begin{abstract}
This study aimed to investigate how employees deal with each other in systems units to keep the information for themselves and its impact on the rest of other employees and on the whole organization as will. The study concluded that hiding information is deemed as key factor for organization solidity, strength and reputation. As all the organization.
\end{abstract}

\section{General Terms}

Hiding Information, Performance, Organization, Information System, SQL (Structured Query Language), Automatic System Management, IS (Information System).

\section{Keywords}

Environment, Wastebasket, Colleague, Automatic, Procedure, Function, Record, Grant, Authorization, Monopoly, Encryption, Decryption, Loop, Programmer, analyst, Designer, Application, Efficiency, Effectiveness.

\section{INTRODUCTION}

Information is deemed as an important and valuable resource; of information technological resources. It is also deemed as a link between data and knowledge in terms of obtaining information from various and distributed data then display the same in several forms by use one of different systems [1].

Information is the main driver of information systems, these systems would not work without this information, and also depends on its modernity, accuracy, comprehensiveness and resources from one hand, while on the other hand, it is information activities used in building these information systems and its management by information staff, since the more available information the more it facilitates the work to perform and achieve the organization aim [1].

The information confidentiality is protecting the concluded information and their activities, without inform others but informing all with its outcomes.

The study indicates that actions confidential keeps workers in concentration situation, following, creation and permanent competition, due to several benefits that may accompany this action, it may be salary increment, rewards, job degrees, differentiation and replacement.

Degree of honest competition among employees and assists to increase its experience and capacity degree to perform hard works instead of waiting information in easy way.

\section{STUDY STATEMENT}

Employees have to cooperate within work environment in the organization in different job fields to achieve organization purposes, but this cooperation is not existing or is not at the desired level among employees within automatic systems management, whereas some hide information from their colloquies within the same unit in the systems department or hide the same away from employees in different units within the same department.

On the bases of this case a few called automatic systems management in most organization as wastebasket, as it exists in our houses due to worse treatment of employees colloquies among themselves in this form or even with other employees in different departments within the organization.

Certain people in most automatic systems department monopolize information that able to integrate information, actions and problems solving that perform works in advance way capable to comprehend several variables, in particular, network administrator for example or databases administrator or even the programmer, so this group has important issues on organization performance continuity. Therefore the information which they have will not be given except for few persons who may work in the same section or it may not be given.

\section{HIDING INFORMATION TERM:}

Hiding information is not coding or encryption process for data by using specific and designed algorithm to conduct encryption process to be converted into a form that cant not read only unless Decryption Algorithm are available [2], but it is hiding information process with same meaning, that is, not showing and display information to other people who are working in the same department. This information is not stored information within database but it is information on how to carry specific actions in building information system or a tool provided by information system to serve information to facilitate work action, programming, development and maintenance. This can be concluded based on practice, experience and training courses etc.

Example: Grant Or Authorization actions for employee's number 111 to insert or modify or delete operations on clients model screen for specific application, to do this action we need to identify user's number in customers' powers table. This needs several procedures in the application itself or even on SQL screen. In this case hiding information occurred among programmers regarding these points or even at data base managerial level with the rest of staff development. In order to keep this employee only capable to do this. 


\section{STUDY IMPORTANCE}

Study importance stems from the following:

1- It explores the extent of capacity and effectiveness through their abilities, qualifications and experiences.

2- Organization's role in the light of competition among employees to achieve its goals

3- Hiding information and its impact on employees and organization.

4- It deems as reference to set up new and alternative information measures

5- To determine various forms of hiding information.

\section{ACTIONS PERFORMANCE WITHIN THE AUTOMATIC SYSTEMS MANAGEMENT (INFORMATION SYSTEMS)}

In most organizations information system management department is confidential department that most of employees in other departments have no right to access, unless there is a need, so their works is to some extent confidential due to role importance they play in organization because of its importance in its strength and continuity and capital information available [4].

Often, the concerned department contains several units such as, firstly: engineering section with its branches, they are equipment engineering and software engineering and maintenance in general. Secondly: development section consists of programmers, analysts, designers and information supporters (helpdesk). Thirdly: protection section and confidential.

Due to large number of majors, their competition and overlapping in information technology, sometimes a collision occurred between the foregoing names through competition to obtain information and invest the same in systems because of its general benefit for organization, in particular for employee personally. Unfortunately, this occurs in automatic systems department that is hiding information from employees and its impact of their work performance and psychological influence. For example: any bank has two units in development section of automatic systems department, the first: banking units, second: managerial unit, each of which has its own staff, for example in management program: section head, supervisors, analysts programs, designers, and follower's user final work the same is applied on banking section [5].

With respect to work performance and execution method at onset it is made through meeting with automatic systems department director with all sections heads illustrating work that must be completed in the next period. Based on sections heads present their views and suggestions without addressing technical works, this related to keep technical works responsibility with each section to execute, so this keeps execution mechanism method for such sections. Later on every head meets with his employees to put a plan for work performance for each employee. So the work is distributed on a number of programmers and analysts in every section, so each employee show his work to his peers without resorting to any purely detailed software. This may be due to topic confidentiality and the exerted time in execution work actions, and employee importance himself in completion the issue, and to connect this idea to his boss and director [3].

For example: Practical case application may has more than method to execute when the programmer is familiar with all these procedures, he will not disclose all but he discloses only one or more, if these procedures are many to implement certain function on certain programming language and maintain the best for himself. For example: the following table shows reading records ranging between one record to 20 records and execute certain measure through reading process for these record that will be executed in one of these cases

Tables 1: Comparison different cases for the same execute

\begin{tabular}{|c|c|c|}
\hline Case (1): & Case (2): & Case (3): \\
\hline $\begin{array}{l}\text { Begin } \\
\text { For } \mathrm{i} \text { in } \\
1 . .20 \text { Loop } \\
\\
\ldots \ldots . . . . . . . . \\
\text { End Loop, } \\
\text { End; }\end{array}$ & $\begin{array}{l}\text { Begin } \\
\text { While } x=<20 \\
\text { Loop } \\
x=x+1 \\
\ldots \ldots \ldots \ldots \ldots . . . . \\
\text { End Loop, } \\
\quad \text { End; }\end{array}$ & $\begin{array}{l}\text { Begin } \\
\text { Loop } \\
X=x+1 \\
\ldots \ldots \ldots \ldots . . \\
\text { Exit when } x=20 \\
\text { End Loop; } \\
\text { End; }\end{array}$ \\
\hline
\end{tabular}

Each of these cases have certain time to execute that differs from other cases, the employee who make these programs may show his peers one of the previous cases but not all and keep the best for himself especially the effectiveness one in execution. This gives his heads a good impression for his exerted efforts and program effectiveness that the rest programs and he as the owner of these feasible ideas has the right to distinguish from others.

In addition, each section completes distinguished work in which other section are not informed, but department director for the contained work of new ideas and a series in business, performance such as building procedure on database level that facilitates search process in table that consists of millions of records or building function on Model Form level that allows amending the staff evaluation after storage process, in this way we see most of automated systems departments operate in competitive environment dominated by information monopoly and disclosure by narrowest means. Competition may be satisfactory competition and sometimes it is other than that due to bad need for information at implementation time and there is no enough time to think about practical solution and there is no response to such need.

Therefore Information Technology employee has to be ready for such situations because of their impact on performance and achieve organization goals and performing works entrusted to him and others impression

\section{HIDING INFORMATION REASONS:}

There are many reasons that lead to hide information from staff and the most important of which is due to [6]: 1- To differentiate distinguishes employees from others in terms of their capabilities and their experience, knowledge and work in all climates and disciplines. 
2- Access difficulty to information due to cost, effort and time.

3- To monopoly valuable information.

4- To claim rewards and annual increases fair.

5- Lack of ability to control the new areas of work or learning.

\subsection{What should employees do upon hiding information?}

Upon employee appointment and starting work he needs basic information to know. Such information is provided to him by anyone either the director or any employees in the managerial level. Then comes employee role to prove him in all aspects. It is imperative to read instructions and laws then the guide related to organization's work.

In computer systems it is necessary for employee to develop himself continuously in this side in the follow-up of any new versions of these software and its relationship with other software and attending training courses at organization expense of the but if it is not available, he has to borne it, due to its impact in improving his abilities and keep up with his colleagues, and share with his colleagues and staff with ideas, suggestions and initiatives and to work in cooperation and servicing staff with all his abilities in any way and stay away from criticism as much as possible and do not complain. Nowadays there are services available on the internet provide valuable information on performance of the work and to find alternatives for additional solutions not only at the level of the measure, but at the basic working level [7].

Also there is a need to participate in associations or organizations and cooperatives software and applied so as to have a clear impact in increasing the knowledge of the members and to participate with them and attend seminars and conferences on a local level and consolidate all in his curriculum vita.

\subsection{Role of the Organization of concealing information:}

The role of organizations management in this respect is very negative and has its own reasons such as: it gets the desired result it wants regarding how to complete it, it is also interested in the department and all departments in business community, through saying named "divide and rule" always and never. The administration is interested in non-cooperation and agreement of staff and establishment of friendships with each other and competes in all shapes forms and methods, even if one of these forms is hiding information rather than pressure from them to claim to improve their situation because they are working in the department that is considered as backbone of the organization. So we see that the staff are always in the follow-up case of events within the organization and on how to keep pace by improving employee of his abilities continuously regardless of information provision of to him or hide since this employee spent a long time in studying the status quo and internal and external training on used software and this is reflected positively on the organization in terms of their access to their targets in the right time [8].

Due to the efficiencies existing in his staff and good reputation carried by the ability of the used systems in all three departments (high, middle and low). We have not to forget that the employee is trying to prove him and his existing in the organization on innovation and creativity and the attempt as much as possible to reduce the management cost which helps to continue to compete in the business community

The main purpose of hiding information on single section level is to create innovations and new possibilities with colleagues while hiding at the level of other sections is fair competition and speed in providing information and service systems department mechanism in particular and the organization in general.

To keep the impact of this procedure negative on staff psychology because it has many effects on employee who has normal productivity, in information field, which may be financial from organization or cooperative and building friendships with work peers.

Eventually the total benefit for the organization of this method, in particular the ability to absorb any new technology emerged and grew up and keeps up, and new generation of staff who has the ability to work in various competitive conditions and in all majors will be obtained. Also exporting these competencies to other cooperatives to the organization interest and perform business in different methods.

As for other departments (Human Resources, Finance, stores, planning, etc.) hiding information is inside between employees, but to a limited extent due to the clarity of works roles that to be completed and performed between staff. Hiding information may between end user system and another in the same section on how to enter information within the information system to perform works faster or hiding may be in calculation of average certain item purchasing prices (item) within the inventory system in buying screen items or in how to write a letter directed to a third party for equipment purchase, where hiding information methods remain in other departments because of limited possibilities among the staff, but within a specific and well-known scope and not, as the case in the wastebasket department (automated systems department), information officer does not give all of his information and ideas, it remains with him as long as there is competition within the department.

\section{METHODOLOGY}

The research used quantities and qualitative approach to achieve the research objectives. A questionnaire was developed and distributed over the research sample.

\subsection{Population and Sampling}

Employees of information technology in banks' head offices in Amman (Jordan) are the targeted population. The study population consists of 160 employees. A random sample is was selected amounting (101).

\subsection{Study Hypotheses:}

Ho-1 There is no statistically significant impact of hiding information among staff on performance of information departments systems.

Ho-2 There is no statistically significant impact of hiding information among staff on strength and durability and sustainability of the banking sector information departments systems.

\section{DATA ANALYSIS 8.1 Demographic Analysis}

The analysis of the data gathered revealed the following results in terms of sample, marital status, age, educational level. 
Table 2: Sampling Distribution by Demographic Variables

\begin{tabular}{|c|c|c|}
\hline Marital Status & Frequency & 74.3 \\
\hline \hline Married & 75 & 25.7 \\
\hline Single & 26 & Percentage \\
\hline Age Group & Frequency & 6.9 \\
\hline Less than 20 years & 7 & 33.7 \\
\hline $21-$ less than 30 years & 34 & 49.5 \\
\hline $31-$ less than 40 years & 50 & 9.9 \\
\hline Above 40 years & 10 & Percentage \\
\hline Education Level & Frequency & 3.0 \\
\hline \hline BSC & 92 & 51.1 \\
\hline \hline Master & 6 & \\
\hline \hline
\end{tabular}

Table 3: Means and Standard Deviations for Sample Responses regarding impact of hiding information among staff on performance of information departments systems

\begin{tabular}{|c|l|c|c|c|c||}
\hline No & \multicolumn{1}{|c|}{ Statements } & Mean & S. D. & Rank & Degree \\
\hline 1 & $\begin{array}{l}\text { Hiding information between staff is considered as an integral part of } \\
\text { organization work in achieving its strategic goals. }\end{array}$ & 3.72 & 1.226 & 4 & High \\
\hline 2 & $\begin{array}{l}\text { Hiding information is considered as an essential process in } \\
\text { efficiency, effectiveness and capabilities of staff development in } \\
\text { information systems. }\end{array}$ & 3.85 & 1.071 & 1 & High \\
\hline 3 & $\begin{array}{l}\text { Hiding information is considered honest compete among the staff and } \\
\text { in evaluation method. }\end{array}$ & 3.39 & 1.149 & Medium \\
\hline 4 & $\begin{array}{l}\text { Hiding information generates a strong conflict to find the best among } \\
\text { staff. }\end{array}$ & 3.80 & 1.058 & 2 & High \\
\hline 5 & $\begin{array}{l}\text { High cost that may be caused by non-incompetent staff (courses, } \\
\text { training, education, work mistakes) may use monopolized }\end{array}$ & 3.54 & 1.136 & 5 & High \\
\hline 6 & $\begin{array}{l}\text { Hiding information mechanism provides banking sector assets } \\
\text { protection. }\end{array}$ & 3.79 & 1.186 & 3 \\
\hline \hline
\end{tabular}


Impact of hiding information among staff on performance of information departments systems was measured by the statements (1-6) from sample's perspective. Table (3) indicate that study sample attitudes regarding impact of hiding information among staff on performance of information departments systems means ranged between (4.14 - 4.38). This indicates positive attitudes of the sample towards impact of hiding information among staff on performance of information departments systems. Moreover statement no. (2) Which states" Hiding information is considered as an essential process in efficiency, effectiveness and capabilities of staff development in information systems" ranked the first, while statement no.(5) which states that" High cost that may be caused by non-incompetent staff (courses, training, education, work mistakes) may use monopolized information for employee personal goals" ranked the last.

Table (2) indicates that $74.3 \%$ of the sample was married and $25.7 \%$ were single. With respect to sample respondents' age, the majority of the respondents $(49.5 \%)$ age ranged from 31 less than 40 years. $33.7 \%$ of the sample their age ranged between 21 - less is 30 years, while $9.9 \%$ their age ranged between 40 years and more $6.9 \%$ of the sample their age is less than 20 years $91.1 \%$ of the sample have BSC degree, while $5.9 \%$ have master degree and 3\% have $\mathrm{PhD}$.

Table 4: Means and Standard Deviations for Sample Responses regarding impact of hiding information among staff on strength and durability and sustainability of the banking sector information departments systems

\begin{tabular}{|c|c|c|c|c|c|}
\hline No & Statements & Mean & S. D. & Rank & Degree \\
\hline 7 & $\begin{array}{l}\text { Hiding information mechanism provides accurate data needed by } \\
\text { each employee. }\end{array}$ & 4.45 & .793 & 7 & High \\
\hline 8 & $\begin{array}{l}\text { Hiding information mechanism assists in activating self-control and } \\
\text { good decision-making. }\end{array}$ & 4.47 & .729 & 5 & High \\
\hline 9 & $\begin{array}{l}\text { Hiding information leads how to deal with the right person because } \\
\text { he is fully aware of problem subject and is able to solve. }\end{array}$ & 4.23 & .870 & 9 & High \\
\hline 10 & $\begin{array}{l}\text { The majority of hiding information among employees occurred in } \\
\text { information systems department more than the rest of the other } \\
\text { departments. }\end{array}$ & 4.36 & .923 & 8 & High \\
\hline 11 & $\begin{array}{l}\text { Hiding information mechanism is considered as way of work } \\
\text { performance and not a goal. }\end{array}$ & 4.56 & .830 & 2 & High \\
\hline 12 & $\begin{array}{l}\text { Hiding information available contributes to bank competitive } \\
\text { strength and rapid response to external requirements. }\end{array}$ & 4.52 & .782 & 4 & High \\
\hline 13 & There is information that requires hiding from the rest of colleagues. & 4.46 & .729 & 6 & High \\
\hline 14 & The information that I have facilitate work procedures. & 4.61 & .583 & 1 & High \\
\hline 15 & $\begin{array}{l}\text { If I donor hide the information from my colleagues they may exploit } \\
\text { against me. }\end{array}$ & 4.55 & .591 & 3 & High \\
\hline & General Mean & 4.47 & .475 & & \\
\hline
\end{tabular}

Impact of hiding information among staff on strength and durability and sustainability of the banking sector information departments systems was measured by the statements (7-15) from sample's perspective. Table (4) indicate that study sample attitudes regarding Impact of hiding information among staff on strength and durability and sustainability of the banking sector information departments systems means ranged between $(436-4.61)$. This indicates positive attitudes of the sample towards Impact of hiding information among staff on strength and durability and sustainability of the banking sector information departments systems. Moreover statement no.(14) which states" The information that I have facilitate work procedures" ranked the first, while statement no.(9) which states that" Hiding information leads how to deal with the right person because he is fully aware of problem subject and is able to solve" ranked the last. 


\subsection{Hypothesis Testing Results:}

Ho-1 there is no statistically significant impact of hiding information among staff on performance of information departments systems

Table (5): First hypothesis testing

\begin{tabular}{|c|c|c|c|c|c|c|c|c|}
\hline Dependent Variable & R & $R^{2}$ & $\begin{array}{c}\text { F } \\
\text { calculated }\end{array}$ & SigF & \multicolumn{4}{|c|}{ Regression } \\
\hline & & & & & Independent & $\beta$ & T-Calculated & Sig \\
& & & & & Variable & & & \\
\hline Performance & .475 & .225 & 28.795 & .000 & $\begin{array}{c}\text { Hiding } \\
\text { information }\end{array}$ & .475 & 5.366 & .000 \\
\hline
\end{tabular}

Results in table (5) indicates the impact of hiding information among staff on performance of information departments systems since $\mathrm{R}$ value between hiding information and performance was (.475) at $(\alpha \leq 0.05)$ level, while $\mathrm{R}^{2}$ is (.225). This means that $22.5 \%$ of changes in attitudes of hiding information are a result of changes in performance. In addition value is $\beta=.475$ which represent the total impact of hiding information on performance which is significant since $\mathrm{T}$ calculated value 5.366. Based on the null hypothesis is rejected and the alternative one is accepted this means that There is statistically significant impact of hiding information among staff on performance of information departments systems.

Ho-2 there is no statistically significant impact of hiding information among staff on strength and durability and sustainability of the banking sector information departments systems

Table 6: Second hypothesis testing

\begin{tabular}{|c|c|c|c|c|c|c|c|c|}
\hline Dependent Variable & $\mathbf{R}$ & $\overline{\mathbf{R}^{2}}$ & $\begin{array}{c}\text { F } \\
\text { calculated }\end{array}$ & SigF & \multicolumn{4}{|c|}{ Regression } \\
\hline & & & & & $\begin{array}{c}\text { Independent } \\
\text { Variable }\end{array}$ & $\beta$ & T-Calculated & Sig \\
\hline Strength & .277 & .077 & 8.217 & .005 & $\begin{array}{c}\text { Hiding } \\
\text { information }\end{array}$ & .277 & 2.867 & .005 \\
\hline
\end{tabular}

Results in table (6) indicates the impact of hiding information among staff on strength and durability and sustainability of the banking sector information departments systems, since $\mathrm{R}$ value between impact of hiding information among staff on strength and durability and sustainability of the banking sector information departments systems was (.277) at $(\alpha \leq 0.05)$ level, while $\mathrm{R}^{2}$ is (.077). This means that $7.7 \%$ of changes in attitudes of impact of hiding information among staff on strength and durability and sustainability of the banking sector

Information departments systems. In addition value is $\beta=.277$ which represent the total impact of hiding information among staff on strength and durability and sustainability of the banking sector information departments systems which is significant since $\mathrm{T}$ calculated value is 2.86 . Based on the null hypothesis is rejected and the alternative one is accepted this means that impact of hiding information among staff on strength and durability and sustainability of the banking sector information departments systems.

\section{CONCLUSIONS}

This study reached the following conclusion:

1. Hiding information is deemed as a style of improving staff efficiency and effectiveness within information systems.

2. Hiding information achieves organization goals indirectly.

3. Hiding information speeding organization response to requirements and external variables.

4. Hiding information is a mean and not an organization objective.

5. There is statistically significant impact of hiding information among staff on performance of information departments systems.

6. There is an impact of hiding information among staff on strength and durability and sustainability of the banking sector information departments systems. 


\section{REFERENCES}

[1] Laudon, Kenneth \& Jane Laudon (2000) Management Information systems, Prentice International. New York.

[2] Al _ Hamami, A. and Al Any, S (2007) Information Security Technology and Protection system, Dar Wael, Amman.

[3] Qutaishat, M (2005) Database Management, Dar Wael, Amman.

[4] Hamami, A.H. and Hamami, M. A. (2008) Information Hiding: Ithra'a Publishing and Distribution, Amman.

[5] Shamsin, R (1998) Oracle 8 A Enhancing Data Base that ensure Information Management Confidentiality and Multiple Informatics Means, computer,
Communication, Electronics Journal, Vo 15 Issue 10, pp 90-91.

[6] Al-Sheri, H (2012) Advanced Digital electronic system and Information confidentiality protection from spying .Arab Journal for safety and training Studies, Volume 28, Issue 56, pp 32-35.

[7] Ahmad, Awed and Hussein, A. (2005) Information Security and Coding Techniques, Al -Hamed For Publishing and distribution, Amman.

[8] Al _ Hamami, A. and Al Any, S (2007) Information Security Technology and Protection system, Dar Wael, Amman. 